\title{
Factors Affecting Consumer Buying Behavior of Mobile Phone Devices
}

\begin{abstract}
Mesay Sata
School of Management and Accounting Hawassa University, Ethiopia

\section{Doi:10.5901/mjss.2013.v4n12p103}

Abstract

The purpose of this study is to investigate the factors affecting the decision of buying mobile phone devices in Hawassa town. In order to accomplish the objectives of the study, a sample of 246 consumers were taken by using simple random sampling technique. Both primary and secondary data were explored. Moreover, six important factors i.e. price, social group, product features, brand name, durability and after sales services were selected and analyzed through the use of correlation and multiple regressions analysis. From the analysis, it was clear that consumer's value price followed by mobile phone features as the most important variable amongst all and it also acted as a motivational force that influences them to go for a mobile phone purchase decision. The study suggested that the mobile phone sellers should consider the above mentioned factors to equate the opportunity.
\end{abstract}

Keywords: Consumer Buying Behavior, Mobile Phone, Consumer Purchase Decision, Hawassa

\section{Introduction}

The development of mobile phones and technologies has been an extended history of innovation and advancements cropped up due to dynamic changes in consumers' needs and preferences. Among these developments, mobile phone devices have had one of the fastest household adoption rates of any technology in the world's modern history (Comer and Wikle, 2008). Nowadays, mobile handsets have become an integral part of human daily life and personal communication across the globe.

In the current highly competitive mobile phone market, manufacturers constantly fight to find additional competitive edge and differentiating elements to persuade consumers to select their brand instead of a competitor's. There are various studies conducted to identify factors that make companies better than their competitors in influencing the customers purchase decision. Consumers' of mobile phone found throughout the world greatly influenced by those different factors affecting mobile phones purchase decision. These factors may be related to the characteristics of the consumer and the features associated with the mobile phones. This leads mobile phone companies to come up with a variety of mobiles with different brands and features. There is various research studies conducted to identify factors affecting consumers' choice of mobile phones. These studies indicated a range of items as a determinant factor influencing purchase decision. These factors include price, features, quality, brand name, durability, social factors and so on (Li 2010; Zheng, 2007; Zhang, 2006; Huang, 2004).

Mobile penetration in Ethiopia is very low when compared to the other African countries (Research ICT Africa, 2010). However, there are 16 million mobile phone subscribers owning various brands of mobile phone. During the mobile phone buying decision process, these subscribers' takes into account numerous factors. However, researchers devoted little attention to factors underlying the mobile phone buying decision process in Ethiopia. This study seeks to know the factors that underlying a person's decision in choosing brand of mobile phone(s) to use. At the end of this study, it will be possible to know the most popular brand of mobile phone in Hawassa city. 


\section{Literature Review}

Consumers are individuals and households that buy the firms product for personal consumption (Kotler, 2004). It often used to describe two different kinds of consuming entities: the personal consumers and the organizational consumers (Krishna, 2010). The activities these consumers undertake when obtaining, consuming, and disposing of products and a service is known as consumer behavior. Consumer behavior involves studying how people buy, what they buy, when they buy and why they buy. When a consumer wanted to make the purchase decision, they will pass through the process through recognition, search information, evaluation, purchase, feedback (Blackwell, Miniard, and Engel, 2006). At last, the consumer will choose a product or brand to consume from various choices in the market. However, these factors affecting the buying behavior of consumers vary due to diverse environmental and individual determinants.

Consumer buying behavior is influenced by two major factors. These factors are individual and environmental. The major categories of individual factors affecting consumer behavior are demographics, consumer Knowledge, perception, learning, motivation, personality, beliefs, attitudes and life styles. The second category of factors is environmental factors. Environmental factors represent those items outside of the individual that affect individual consumer's decision making process. These factors include culture, social class, reference group, family and household. The above mentioned factors are the major determinants behind the decision of consumers to opt a given good or service (Blackwell, Miniard, and Engel, 2006).

Ethiopia is a developing country and has witnessed fast economic growth and developments in mobile telecommunication penetration in recent years. Due to these reasons, there is a dynamic increase in the number of mobile phone device users. This attracted large number of international firms to enter into mobile industry and offer various brands of mobile phones. However, the choice of consumer is diverse due to various factors associated with consumer behavior. In this context, it is important to study the various factors which shape the consumers mind during the purchase of mobile phone devices.

According to Karjaluoto et al. (2005), price, brand, interface, and properties tends to have the most influential factors affecting the actual choice amongst mobile phone brands. Ling, Hwang and Salvendy (2007) surveyed college students to identify their preference of their current mobile phone. The results of their survey indicated that the physical appearance, size and menu organization of the mobile phones are the most determinant factors affecting the choice of mobile phones.

Mack and Sharples (2009) showed that usability in the most important determinant of mobile choice; other attributes particularly features, aesthetics and cost are other factors that have implication on the choice of mobile phone brand. In other study conducted by Kumar (2012), price, quality and style functions as the most influential factors affecting the choice of mobile phones. Moreover, Saif et al, 2012 selected four important factors i.e. price, size/shape, new technology features and brand name and analyzed their impact on consumers' buying behavior. According to his result, consumer's value new technology features as the most important variable that influences consumers' to go for a new mobile phone purchase decision.

Eric and Bright (2008) conducted a study on factors that determine the choice of brands of mobile phone in Ghana specifically Kumasi Metropolis. Accordingly, the results of the study showed that the first most important factor is reliable quality of the mobile phone brand and the other factor is user-friendliness of the brand of the mobile phone. Likewise, Das (2012) conducted an empirical research based on survey method on factors influencing buying behavior of youth consumers towards mobile handsets in coastal districts of Odisha located in India. According to the study, a handset of reputed brand, smart appearance, and with advanced value added features, pleasurability and usability; is the choice of young consumers; females in gender-group, post-graduates in level of education-group, students in occupational group, urban residents in geographical area group plays most prominent role in buying decision of a mobile handset.

Pakola et al. (2010) attempted to investigate consumer purchasing motives in cellular phone markets. The results indicated that while price and properties were the most influential factors affecting the purchase of a new mobile phone, price, audibility and friends' operator were regarded as the most important in the 
choice of the mobile phone operator. As well, Saif (2012) analyzed the factors affecting consumers' choice of mobile phone selection in Pakistan. The results indicated that consumer's value new technology features as the most important variable amongst all and it also acts as a motivational force that influences them to go for a new handset purchase decision.

Subramanyam and Venkateswarlu (2012) conducted a study on factors influencing buyer behavior of mobile phone buyers in Kadapa district in India. The researchers studied the various types of marketing strategies adopted by market to acquire the attention and cognition of both existing and potential customers, and to study what role these marketing strategies play in consumer buying process. According to the results, income, advertising and level of education in a family are the determining factors of owning a mobile phone set. Malasi (2012) examined the influence of product attributes on mobile phone preference among undergraduate university students in Kenya. The study indicated that varying the product attributes' has an influence on the undergraduate students' preferences on mobile phones. Various aspects of product and brand attributes were considered such as color themes, visible name labels, and mobile phone with variety of models, packaging for safety, degree of awareness on safety issues, look and design of the phone.

Based on previous research studies and literatures reviewed the following conceptual framework and research hypothesis were developed for this research project. Accordingly, six independent variable (i.e. price, social factors, durability, brand name, product features and after sales services) thought to influence the dependent variable (i.e. decision to by) are identified.

Figure1: Conceptual framework of the study

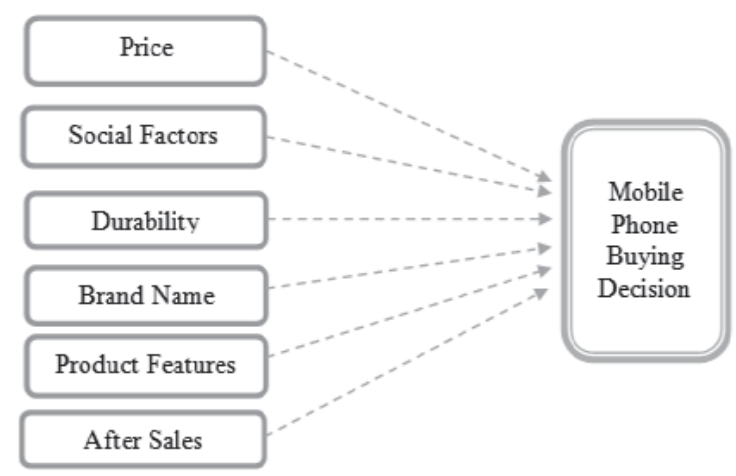

The research is examined through the following hypotheses:

- $\mathrm{H}_{1}$ : The social factors have a positive influence on the consumers' mobile phone buying decision.

- $\mathrm{H}_{2}$ : Durability has a positive influence on consumers' mobile phone buying decision.

- $\mathrm{H}_{3}$ : Price has a positive effect on consumer's mobile phone buying decision.

- $\mathrm{H}_{4}$ : After sales services influence consumers' decision to acquire mobile phones.

- $\mathrm{H}_{5}$ : Mobile phones features influence consumers' decision to acquire mobile phones.

\section{Materials and Methods}

This research was conducted in Hawassa city. Hawassa is located at 70' 30" latitude north and 80' 29"east longitude also located south of Addis at $275 \mathrm{~km}$. Based on the 2007 Census conducted by the Central Statistical Agency of Ethiopia, Hawassa has a total population of 258,808, of whom 133,123 are men and 125,685 women. The study is aimed at identifying factors behind consumers' decision to purchase mobile phones in Hawassa city. The people in the Hawassa are mostly employees working for public, private or 
nongovernmental organizations. Hence, the study population constitutes of all the mobile phone owners found in Hawassa city. In order to select the sample respondents, simple random sampling method was employed. This method makes all the members of the population an equal chance to be included in the sample. Once a sampling technique has been chosen the next step is to calculate the appropriate size of the sample. The minimum required sample size for this study is specified by using the Cochran (1977) sample size determination formula:

$$
n=\left(\frac{z}{e}\right)^{2} p q=\left(\frac{1.96}{0.05}\right)(0.2)(0.8)=246
$$

In this study, both quantitative and qualitative data were used. The qualitative data was obtained from the primary sources of data. On the other hand, the quantitative data was collected from both primary and secondary sources of data. The primary data was collected through administrating questionnaire. The secondary data was obtained from reports, manuals, and different journals, publications for assessing existing findings, internet, books and documents.

The main instrument of data collection was questionnaire. The structured questionnaire itself was designed so as to make it easy to answer and to cover most of the common research questions. Furthermore, the questionnaire was designed so as to elicit information on both demographic and product use aspects of the respondents. The questionnaire was translated in to local language (i.e. Amharic) for easy understanding and simplicity.

In this research project, the questionnaire was pre-tested on a number of respondents who were similar to those who were to be included in the study in terms of background characteristics in order to ensure that the instructions and the meanings of the questions were simple, clear, unambiguous and beneficial to the subjects. A total of six individuals were participated in the pilot study. Changes were made accordingly and the input of these individuals was taken into consideration.

To meet the specified research objectives, both qualitative and quantitative data analysis were used for the study purpose. Both descriptive and inferential statistics methods of data analysis were employed. Descriptive statistics like frequency distributions, graphs, charts, cross-tabulations and inferential statistics like correlation and multiple regressions was used to elicit meaningful information. The data entry and analysis was performed by using Microsoft Excel and Statistical Package for Social Science (SPSS) version 20.

\section{Results and Discussion}

During the survey, 246 questionnaires were distributed to purposively selected mobile phones shops (centers) in Hawassa town. Unfortunately 22 questionnaires were not responded appropriately. So the analysis was made based on 231 responded questionnaires. The table below deals with the basic demographic characteristics of the respondents including age, gender, income, marital status, educational qualification and occupation of the respondents included in this research project.

Table 1: Demographic characteristics of respondents'

\begin{tabular}{|l|c|c|}
\hline \multicolumn{1}{|c|}{ Item } & Number & Percentage \\
\hline Age & & \\
Below 18 & 21 & 9.1 \\
18 to 25 & 84 & 36.4 \\
26 to 35 & 81 & 35.1 \\
Above 35 & 45 & 19.5 \\
Gender & & \\
Male & 153 & 66.2 \\
Female & 78 & 33.8 \\
& & \\
& &
\end{tabular}




\begin{tabular}{|l|c|c|} 
Education & & \\
Secondary School & 24 & 10.4 \\
Diploma & 51 & 22.1 \\
Degree & 120 & 51.9 \\
Above Degree & 36 & 15.6 \\
Occupation & & \\
Student & 72 & 31.2 \\
Self Employed & 27 & 11.7 \\
Employed & 132 & 54.5 \\
Unemployed & 6 & 2.6 \\
Marital Status & & \\
Single & 147 & 63.6 \\
Married & 75 & 32.5 \\
Divorced & 9 & 3.9 \\
Income & & \\
Below 500 & 54 & 23.4 \\
500 to 1,000 & 27 & 11.7 \\
1,000 to 3,000 & 57 & 24.7 \\
3,000 to 5,000 & 72 & 31.2 \\
5,000 to 10,000 & 12 & 5.2 \\
Above 10,000 & 9 & 3.9 \\
\hline \multicolumn{1}{|c|}{ Total } & 231 & 100 \\
\hline
\end{tabular}

Table 1 indicates that 9.1 percent of the respondents are below 18 years old, 36.4 percent of the respondents fall within the ages of 18 - 25 years, while 35.1 percent of the respondents' falls within 26 - 35 years and 19.5 percent of the respondents' falls above 35 years. Therefore, it indicates greater number of respondent falls within 18 to 25 years which represents 84 respondents and followed by 26 to 35 years which represent 81 respondents. The table depicts 66 percent of the respondents are male and the rest 34 percents are females. It shows that the majority of the respondents are holders of first degree (65.8\%) followed by diploma (21.6\%), secondary (9.1\%) and above first degree (3.5\%) respectively. Accordingly, majority of the respondent are employees in public, private, government or nongovernmental organization representing $54 \%$ of the respondents followed by students (32\%) and self-employed (13\%). Moreover, there are few respondents considered as unemployed (1\%).

Regarding marital status of the respondents, 64 percent of the respondents are single, 32 percent of them are married and the remaining 4 percent of the respondents are divorced. Moreover, table 1 shows that 54 of the respondents earns income below $\mathrm{Br}$. 500 which represents $23.4 \%$, it shows that 27 of the respondents earns income between $\mathrm{Br} .500$ - Br.1,000 which represents $11.7 \%, 57$ out of 231 respondents earns income between $\mathrm{Br}$. 1,000 - Br. 3,000 which represents 24.7\%, 72 of the respondents earns income between $\mathrm{Br}$. 3,000 - Br. 5,000 which represents 31.2\%, 12 of the respondents earns income between $\mathrm{Br}$. $5,000-10,000$ which represents $5.2 \%$, while 9 of the respondents earns income above $\mathrm{Br}$. 10,000 which represents $3.9 \%$.

\subsection{Brand of Mobile Phone Owned}

The figure below exhibits the respondents' current handset usage and to what brand the consumers would prefer to change in the future. Accordingly, $67 \%$ of the respondents with overwhelming majority currently use Nokia mobile phones followed by Techno (11.8\%), Other Chinese brands (9.2\%) and Samsung (5.3\%). 
Figure 2: Type of mobile phone brand owned by respondents

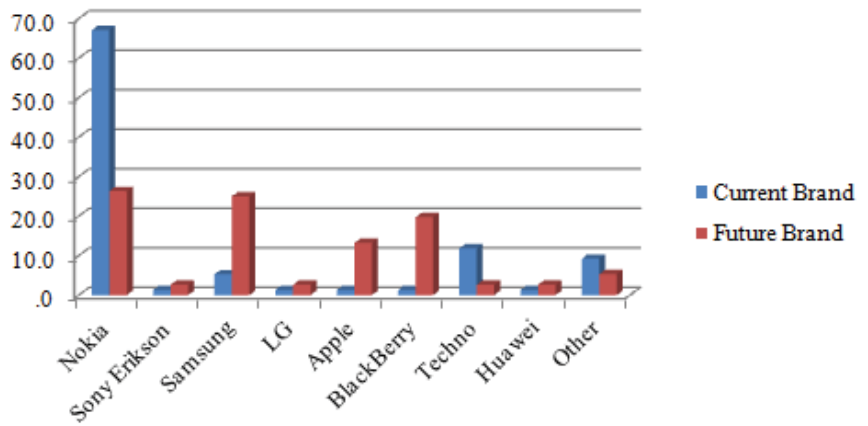

The least owned mobile brands are Sony Erikson, LG, Apple, BlackBerry and Huawei accounting together for $6.5 \%$ of the respondents' mobile phone ownership in Hawassa. Both Nokia and Techno offer variety phones with affordable prices that make them to be preferred by the buyers. Generally, the result of the study indicates Nokia is the dominant and widely owned mobile phone device in Hawassa.

Moreover, the above graph shows the preferred mobile phone brands respondents intends to purchase in the future period. Most respondents want to shift to Samsung in the future irrespective of what they are using right now. Nokia will be the dominant brand with $26 \%$ of the respondents continues to use but half of the current users planning to shift to other brands such as Samsung, Apple and BlackBerry. An interesting observation here is, among the current users of Nokia, there are around $39 \%$ want to stay with the same brand while the remaining want to shift to other brands. Surprisingly, there is also a group of Nokia users (around 16\%) which wants to shift to Samsung as their next handset and around $35 \%$ of the respondents want to shift either to Apple or BlackBerry. Demand for Nokia has been great in the Ethiopia market and seems will be quite good in declining demand pattern in the future. Moreover, the market looks promising for mobile phones with touch screen features like Samsung, Apple and BlackBerry.

\subsection{Descriptive Statistics Results of Independent Variables}

Table 2 portrays the descriptive statistics results (i.e. mean and standard deviation) results of the six independent variables. As shown in the table, the prime factor with the highest mean value is after sales service (mean $=3.6)$ followed by brand name (mean $=3.448$ ), product features (mean $=3.445)$ and durability $($ mean $=3.34)$ respectively. The two independent variables with the least mean score are price (mean $=3.38)$ and social factors (mean $=3.03$ ). The results indicate the performance of the variable in terms of the expectation of the consumer. Overall, the mean results are close to each other.

Table 2: Mean and standard deviation results of independent variables

\begin{tabular}{|l|c|c|c|}
\hline \multicolumn{1}{|c|}{ Variables } & Frequency & Mean & Std. Deviation \\
\hline Price & 231 & 3.3822 & .85174 \\
\hline Social Influence & 231 & 3.0285 & .88511 \\
\hline Durability & 231 & 3.3422 & .90862 \\
\hline Brand Name & 231 & 3.4478 & .84036 \\
\hline Product Features & 231 & 3.4447 & .78492 \\
\hline After Sales Service & 231 & 3.6009 & .85031 \\
\hline
\end{tabular}




\subsection{Pearson Correlation Result of the Variables}

Table 3 shows the correlation between six factors i.e. price, social influence, durability, brand, product features and after sales service with the decision to buy a mobile phone device. Accordingly, all factors have a positive and significant relationship with the decision to buy a mobile phone. However, the degree of correlation among the factors is different with the highest correlation value of price $(0.900)$ followed by product feature (0.876) durability (0.557) and brand image (0.555) of the mobile phone. In contrary, the least correlated factor is after sales service $(0.454)$ followed by the social influences $(0.461)$.

According to table 4.5, the highly correlated factor that influences the decision to acquire a mobile phone is the selling price of the cellular device. Accordingly, the price of a product is an important factor that cannot be overlooked in a study of consumer behavior. Majority of the respondents indicated price as main consideration when they decide to buy their mobile phone. The variation in mobile price will influence the behavior of individuals to purchase the device. The results of this research study coincide with the result of other studies conducted in the consumer buying decision of mobile phones. According to Saif (2012), a study conducted in Pakistan, price was valued as the most motivating factor in mobile purchase decision. Moreover, the study conducted by Pakola et al. (2010) in Finland regarded price as the most important motive affecting the decision to purchase mobile phones.

Table 3: Pearson correlation result of the variable

\begin{tabular}{|c|c|c|}
\hline Variables & & Decision to Buy \\
\hline \multirow{3}{*}{ Price } & Pearson Correlation & $.900 * *$ \\
\hline & Sig. (2-tailed) & .000 \\
\hline & $\mathrm{N}$ & 231 \\
\hline \multirow{3}{*}{ Social Influence } & Pearson Correlation & $.461^{\star \star}$ \\
\hline & Sig. (2-tailed) & .000 \\
\hline & N & 231 \\
\hline \multirow{3}{*}{ Durability } & Pearson Correlation & $.557^{\star \star}$ \\
\hline & Sig. (2-tailed) & .000 \\
\hline & $\mathrm{N}$ & 231 \\
\hline \multirow{3}{*}{ Brand Name } & Pearson Correlation & $.555^{\star \star}$ \\
\hline & Sig. (2-tailed) & .000 \\
\hline & N & 231 \\
\hline \multirow{3}{*}{ Product Feature } & Pearson Correlation & $.876^{\star \star}$ \\
\hline & Sig. (2-tailed) & .000 \\
\hline & $\mathrm{N}$ & 231 \\
\hline \multirow{3}{*}{ After Sales Service } & Pearson Correlation & $.454^{\star \star}$ \\
\hline & Sig. (2-tailed) & .000 \\
\hline & $\mathrm{N}$ & 231 \\
\hline
\end{tabular}

The mobile phone feature is the second important factor correlated with the consumer decision to buy the device. Mobile phone features include internet connection, Bluetooth, video, color, FM, media player, design, touch screen, store, size, available accessories, speaker and weight. All these factors considered to have 
relationship with the decision to buy the mobile devices. The results of this research study corresponds with previous researches conducted in other countries (Pakola et al., 2010; Das, 2012; Saif, 2012; Malasi, 2012; Eric and Bright, 2008) that considers the features of mobile phone as a dominant factor in consumer buying decision.

The other two factors equally correlated and have moderate relationships with the decision to buy are brand name and durability of mobile phones with Pearson correlation coefficient of 0.557 and 0.555 respectively. Both factors are highly associated with the quality of a given product. Durability is associated with the use of a mobile device for a long period without any defects. High quality mobile phone works well and nothing goes wrong for a long period of time. Other similar studies also indicated that consumers prefer internationally recognized and well known brands of mobile phone (Das, 2012; Zhou and Shanturkovska, 2011). According the table 3 , the least correlated and moderately related determinants of consumer buying decisions are social influences and after sales services with Pearson correlation coefficient of 0.461 and 0.454 respectively. These two factors moderately influence the decision to buy a mobile phone device. However, their degree of correlation is the least as compared to other factors included in this study. This result can be justified with similar studies conducted on the factors affecting the choice of mobile phones (Subramanyam and Venkateswarlu, 2012; Pakola et al., 2010).

\subsection{Multiple Regressions Analysis}

In this study, there are six independent variables namely price, after sales service, brand name, social influence, durability and product features considered to influence the buying decision of mobile phone devices. Before analyzing the data using multiple regressions, it is appropriate to test the presence of multicollinearity among the independent variables. It indicated that the maximum correlation coefficient is 0.724 that represent less likely to find multicollinearity among the independent variable.

To test the effects of these variables on the decision to buy a mobile phone device, the study used the multiple regression analysis. The table below shows the multiple regression result between six independent variables and the decision to purchase a mobile phone device in Hawassa. It indicates that all the six independent variables (price, social influence, durability, brand name, product feature and after sales service) combined significantly influence the consumers buying decision of mobile phone devices. The leading factor is price followed by product features and durability.

Table 4: Multiple regression results of dependent and independent variables

\begin{tabular}{|c|c|c|c|c|c|}
\hline \multirow{2}{*}{ Model } & \multicolumn{2}{|l|}{ Unstandardized Coefficients } & Standardized Coefficients & \multirow{2}{*}{$\mathrm{t}$} & \multirow{2}{*}{ Sig. } \\
\cline { 2 - 4 } & $\mathrm{B}$ & Std. Error & Beta & & \\
\hline (Constant) & -.694 & .225 & & -3.089 & .003 \\
\hline Price & .589 & .084 & .525 & 7.028 & .000 \\
\hline Social Influence & .066 & .053 & .062 & 1.263 & .211 \\
\hline Durability & .112 & .062 & .107 & 1.826 & .042 \\
\hline Brand Name & .039 & .069 & .034 & .569 & .571 \\
\hline Product Feature & .407 & .097 & .334 & 4.183 & .000 \\
\hline After Sales Services & .020 & .054 & .018 & .381 & .705 \\
\hline $\begin{array}{l}\text { Dependent Variable: Decision to Buy } \\
\text { R Square: 0.881 } \\
\text { Adjusted R Square: 0.870 }\end{array}$ & & & & \\
\hline
\end{tabular}


The adjusted $\mathrm{R}^{2}$ of 0.87 indicates 87 percent of variances in consumer buying decision can be predicted by the six variables used in this research study. Accordingly, there are other variables that influence buying decision of individuals represented by the remaining 13 percent. But the majority of the variance in buying decision can be predicted by the six variables included in this study.

\section{Conclusions and Recommendations}

\subsection{Conclusions}

The objective of this research was to investigate the underlying factors that determine the decision to purchase mobile phone devices. According to the study, majority of the consumers own Nokia mobile phones. Moreover, most of Nokia mobile phone users have a plan to shift to other brands such as Samsung, Apple and BlackBerry.

According the Pearson correlation results, price is the dominant factor affecting the decision to buy mobile phone. Secondly, the features incorporated in a mobile hand set are the most important factor which is considered by the consumers while purchasing the mobile phone. However, all features of mobile phones are not equally important. The other factors equally correlated and have moderate relationships with the decision to buy are brand name and durability of mobile phones. Both the factors are highly associated with the quality of mobile phone devices. The least correlated factors are after sales service and social influences.

This study used multiple regressions analysis to test the effects of six independent variables (price, social influence, durability, brand name, product feature and after sales service) on the decision to buy a mobile phone device. All the six independent variables combined significantly influence the consumers buying decision of mobile phone devices. The leading factor is price followed by product features and durability.

\subsection{Recommendations}

Nokia is still first in the mobile phone market but needs to keep abreast of technological changes as Samsung are taking market share away from Nokia. This loss of market share is partly due to Nokia's refusal to incorporate new technologies, and also to the improvement in quality in the manufacture of Samsung mobile phones. Each mobile phone manufacturer should carefully re-think its strategy when producing, marketing and distributing these devices and focus on brand personality, brand positioning, product design and differentiation.

People attracted towards newer technology and will be able to shift from one mobile phone to another if it uses better technology. Mobile phone companies should carry out periodic survey to help in identifying these new technology features and decide which ones to add to its product. Moreover, by determining which combination of these features match the current trends and consumer needs would be cost effective to the mobile phone companies. In turn, product design is also very important in the success of the brand.

Manufacturers of different mobile brands are improving on the durability and quality of the brand, they should also consider the price of selling it so as to make it affordable to all persons. It is recommended that companies concentrate more on developing quality and affordable mobile phones and spend more time on enhancing their products to offer it at lower prices which can be done by employing cost reduction measures.

\section{References}

Blackwell, RD, Miniard, PW \& Engel, JF (2006). Consumer behavior, 10th edn, Thomson South-Western, Boston. Cochran, W. G. (1977). Sampling techniques (3rd ed.). New York: John Wiley \& Sons.

Comer and T. A. Wikle (2008), Worldwide diffusion of the cellular telephone, (1995-2005). The Professional Geographer, $60(2), 252-269$. 
Das, D. (2012). An empirical study of factors influencing buying behaviour of youth consumers towards mobile handsets: A case study in coastal distrcts of Odisha. Asian Journal of Research in Business Economics and Management, 2(4), 68-82.

Engel and R. Blackwell. (1982). Consumer Behavior, 4th ed. CBS College Publishing

Hakoama and S. Hakoyama, (2011). The impact of cell phone use on social networking and development among college students, The AABSS Journal, 15 (2011), 1-20.

Karjaluoto et al. (2005). Factors affecting consumer choice of mobile phones: Two studies from Finland, Journal of Euromarketing, 14(3), 59-82.

Kotler, P. (2004). Ten deadly marketing sins: signs and solutions. Wiley

Li, S., \& Li, Y. (2010). An Exploration of the Psychological Factors Influencing College Students' Consumption of Mobile Phone in West China. International Journal of Business and Management, 5(9), P132.

Ling, W. Hwang and G. Salvendy (2006). Diversified users' satisfaction with advanced mobile phone features, Universal Access in the Information Society, 5(2), 239-249.

Mack and S. Sharples (2009). The importance of usability in product choice: A mobile phone case study, Ergonomics, 52(12), 1514-1528.

Malasi J. M. (2012). Influence of Product Attributes on Mobile Phone preference among university students: A Case of Undergraduate students. International Journal of Academic Research in Economics and Management Sciences. 1(6), 10 - 16

Pakol et al, (2010). An investigation of consumer behavior in mobile phone markets in Finland. In Submission to the 32nd EMAC conference, Track: New Technologies and E-Marketing.

Saif, N., Razzaq, N., Amad, M., \& Gul, S. (2012). Factors Affecting Consumers' Choice of Mobile Phone Selection in Pakistan. European Journal of Business and Management, 4(12), 16-26.

Subramanyam and Venkateswarlu (2012). Factors Influencing Buyer Behaviour of Mobile Phone Buyers in Kadapa District. Indian Journal of Research, 1(11), 3-5

Zhou, N., \& Shanturkovska, G. (2011). Chinese Consumer Behavior in the Mobile Phone Market: Nokia Case (Doctoral dissertation, Gotland University) 